\title{
Depression and anxiety as risk factors for female sexual pain
}

\author{
M. R. Soltan ${ }^{1 *}$, T. A. Abdel Raheem², S. S. Soliman³ , N. M. Saleh² and B. H. Khatery ${ }^{2}$
}

\begin{abstract}
Background: Female sexual pain is a complex multifactorial condition. Most of researches have focused on underlying biomedical factors. Although psychological, psychiatric, and relational factors have been studied as possible correlates, limited research has been made in this area about the Egyptian population. The present study aimed to evaluate prevalence of female sexual pain among a sample of Egyptian females and detect its correlation with depression and anxiety. Female sexual function index (FSFI) was used to evaluate sexual pain in 450 women calculating their pain domain scores. Their scores were correlated to demographic data, genital health complaints, depression, and anxiety symptoms.

Results: The prevalence of marked severe sexual pain was $31.6 \%$ and that of trivial pain was $68.4 \%$ in the studied group. In the study group, 75 (16.7\%) females had depressive symptoms, and 40 (8.9\%) females had anxiety symptoms. Patients with severe depression had significantly marked severe pain than patients with minimal depression ( $p<0.001$ respectively). Patients with severe anxiety had significantly lower pain score than patients without $(p<0.001)$. Pain score had significant negative correlation with each of the depression score $(r-0.524, p$ $<0.001)$ and the anxiety score $(r-0.305, p<0.001)$. Patients with gynecological causes especially fungal infection had significantly severe marked pain than patients without any other physical causes $(<0.001)$.

Conclusions: Anxiety, depression, and the presence of gynecological causes especially fungal infection were significantly independent risk factors for more sexual pain.
\end{abstract}

Keywords: Female, Sexual pain, Anxiety, Depression, Egypt

\section{Background}

Pain can be a defining characteristic of sexual disorders. Dyspareunia, or pain during intercourse, affects between 12 and $44 \%$ of women [1-3].

Female sexual pain is a complex multi-factorial condition. Most of researches have focused on underlying biomedical factors. Although psychological, psychiatric, and relational factors have been studied as possible correlates, data are still controversial $[4,5]$.

Elevated rates of sexual problems have been reported in women diagnosed with panic disorder, anxiety disorders, and depression that have been associated with decreased

\footnotetext{
* Correspondence: mohamedsoltan1979@gmail.com

1 Department of Psychiatry, Faculty of Medicine, Fayoum University, P.O. Box 63514, Fayoum, Egypt

Full list of author information is available at the end of the article
}

lubrication, decreased sexual satisfaction, increased pain during intercourse or sexual activity, and more orgasmic problems [6].

Some of female sexual pain etiologies are vulvovaginal candidiasis, pelvic inflammatory diseases, chronic pelvic pain, and painful outcomes of delivery [7].

The aim of this study is to evaluate prevalence of female sexual pain among a sample of Egyptian females and to estimate the association between female sexual pain and both of anxiety and depression in Fayoum governorate, Egypt.

\section{Methods}

This is a cross-sectional study which included 450 married sexually active females evaluating their sexual pain. Four hundred and fifty females aged 18-66 years old were selected from three districts of Fayoum governorate (Fayoum
Springer Open (c) The Author(s). 2020 Open Access This article is licensed under a Creative Commons Attribution 4.0 International License, which permits use, sharing, adaptation, distribution and reproduction in any medium or format, as long as you give appropriate credit to the original author(s) and the source, provide a link to the Creative Commons licence, and indicate if changes were made. The images or other third party material in this article are included in the article's Creative Commons licence, unless indicated otherwise in a credit line to the material. If material is not included in the article's Creative Commons licence and your intended use is not permitted by statutory regulation or exceeds the permitted use, you will need to obtain permission directly from the copyright holder. To view a copy of this licence, visit http://creativecommons.org/licenses/by/4.0/. 
district, Sennores, and Itsa). They were selected randomly (simple random method) from primary health care centers, dermatology and family planning clinics of Fayoum University, and general hospitals of the governorate. Subjects who had no sexual activity within the past month, unmarried, divorced, or widow were excluded from the study.

This study was approved by the Ethical committee of Faculty of Medicine, Fayoum University, and was done in accordance to the Declaration of Helsinki. Before obtaining informed consent from the participants, full explanation was given about the nature and aim of the study. They volunteered to participate and had the right to end their participation at any stage of the interview. All participants' information was kept confidential and was used only for research purposes.

Subjects were assessed for the following:

1. Demographic characteristics including age, educational level, age of marriage, occupation, etc.

2. Assessment of gynecological and past medical history to search for risk factors including chronic disease (e.g., hypertension, cardiovascular disease, neurological disease, or diabetes), previous pelvic surgery (gynecologic, urologic, or colorectal surgeries), menstrual cycle regularities, contraception methods, and genital causes of pain as skin rash, ulcers, inflammation, and others.

3. Sexual functions using a self-administered detailed 19item questionnaire (female sexual function index (FSFI)) [8] which assess the sexual functioning during the past 4 weeks. The Arabic validated version of FSFI [9] was used to assess the sexual function of the subjects.

According to the FSFI, sexual function domains included sexual desire, arousal, lubrication, orgasm, satisfaction, and pain during sexual intercourse. Here, we calculated domain score for pain only as it was our concern in this study.

Pain was assessed as frequency during vaginal penetration, frequency following vaginal penetration, and level during or following vaginal penetration with 3 questions 17,18 , and 19 respectively (score range $0-5$ for each question). Pain score was obtained by adding the pain domain score and was calculated by multiplying the sum by the pain domain factor (0.4).

Pain score was analyzed as zero for no pain (no sexual activity) and from 1-6 for pain. According to FSFI, one is minimum score (maximum degree of pain) while 6 is maximum score (very low or no pain).

The pain score was categorized into marked and trivial pain based on a cutoff $\leq 3.6$ for marked pain and $>3.6$ for trivial pain. This cutoff represents pain of high frequency, high degree, or both. This cutoff was calculated as the sum of the choices made by the patients for questions 17,18 , and 19 as follows:
Answers for questions 17 and 18 include sometimes, most times, almost always, or always (3-1), and answer for question 19 include moderate, high, or very high (3-1). The sum of these three questions was then multiplied by the pain domain factor (0.4).

\section{Psychiatric assessment}

Structured Clinical Interview based on DSM-IV (SCIDI) [10] Arabic version [11]: It is used to diagnose an axis I diagnosis. It is applied to the case group for diagnosis of anxiety and depressive disorders. It is a semi-structured diagnostic interview based on DSM-IV that had been modified to DSM-5 clinical criteria. It is considered the standard interview to verify diagnosis in clinical trials and is extensively used in other forms of psychiatric research.

Beck Depression scale by Beck et al. [12] and Arabic version by Abdel-Khalek [13]: This is a self-report scale designed to assess DSM-IV-defined symptoms of depression such as sadness, guilt, loss of interest, social withdrawal, increase and decrease in appetite or sleep, suicidal ideation, and other behavioral manifestations of depression over time to monitor symptoms and to assess response to therapeutic interventions. It has an acceptable degree of validity, as it evaluates a wide variety of symptoms and attitudes associated with depression.

The inventory is composed of 21 statements on a fourpoint scale, with the patient selecting the one that best matches his or her current state. Each statement corresponds to a specific behavioral manifestation. Responses to each question are scored on a scale from $0-3$, equivalent to no, mild, moderate, or severe disturbances. The score range of the inventory varies from 0 to 63 , where a higher score indicates higher depressive symptom severity. According to Beck et al. [14], the scoring range is as follows: 0-13 indicate no or minimal depression, 14-19 indicate mild depression, 20-28 indicate moderate depression, and 29-63 indicate severe depression.

Beck Anxiety scale by Beck et al. [15] and Arabic version by Al-Issa et al. [16]: Beck Anxiety Inventory (BAI) is a 21-item multiple-choice self-report inventory that measures the severity of an anxiety. Each of the items on the Beck Anxiety Inventory is a simple description of a symptom of anxiety in one of its four expressed aspects: (A) subjective (e.g., "unable to relax"), (B) neurophysiologic (e.g., "numbness or tingling"), (C) autonomic (e.g., "feeling hot"), or (D panic-related (e.g., "fear of losing control"). It has acceptable reliability and validity.

Respondents are asked to report the extent to which they have been anxious by each of the 21 symptoms in the week preceding (including the day of) their completion of the BAI. Each symptom item has four possible answer choices: not at all, mildly (it did not bother me much), moderately (it was very unpleasant, but I could stand it), and severely (I 
could barely stand it). The clinician assigns the following values to each response: not at all $=0$, mildly $=1$, moderately $=2$, and severely $=3$. The values for each item are summed yielding an overall or total score for the 21 symptoms that can range between 0 and 63 points. Scores from 0 to 7 indicate a minimal level of anxiety. Scores from 8 to 15 indicate mild level of anxiety. Scores from 16 to 25 indicate moderate level of anxiety. Scores from 26 to 63 indicate severe level of anxiety.

\section{Statistical methods of data analysis}

Results were analyzed by the statistical package for social science (SPSS) version 23 [17]. Quantitative data were subjected to Shapiro-Wilk test to determine the distribution and method of analysis. Qualitative (categorical) data were presented by frequency and percentage. Quantitative data were presented by mean $\pm \mathrm{SD}$, median, and range. Mann-Whitney ( $\mathrm{Z}$ test) and Kruskal-Wallis Test were used for non-parametric data. Spearman linear correlation coefficient $(r)$ was estimated to show the relationship between quantitative parameters. Linear regression was used to ascertain the effect of possible risk factors on the pain score [18].

\section{Results}

The demographic data of the study population is summarized in (Table 1). This study included four hundred and fifty women living in Fayoum governorate. The age of the study group ranged between 18 and 66 years with a mean \pm SD of $31.68 \pm 9.26$, and the age at marriage ranged between 12 and 40 years with a mean \pm SD of $19.43 \pm 3.69$. The husband age ranged between 22 and 75 years old with mean \pm SD of $38.33 \pm 10.85$. Sex acts/ week were between 1 and 7 times with mean \pm SD of $2.44 \pm 0.85$ (Table 1 ).

As regard common causes of genital and gynecological pain over the past 4 weeks in the study participants, the most common cause was fungal infections, 95 (21.1\%) females, then vaginal prolapse, genital wart, genital ulcer, and intrauterine adhesions (Table 1).

In the study group, 75 (16.7\%) females had depressive symptoms as regards Beck Depression scale: one $(0.2 \%)$ female had mild depression, 11 (2.4\%) females had moderate depression, and 63 (14\%) females had severe depression. As regards anxiety, 40 (8.9\%) females had anxiety symptoms Beck Anxiety scale: $3(0.7 \%)$ females had moderate degree of anxiety and $37(8.2 \%)$ females had severe anxiety symptoms (Table 2).

The mean sexual pain among the included females was $4.75 \pm 1.50$ ranging from 0 to 6.0 (median 6). Marked pain $(\leq 3.6)$ was reported by 142 females $(31.6 \%$, 95\% CI 27.3-35.8), while trivial pain was reported by 308 females (68.4\%, 95\% CI 64.2-72.7) (Fig. 1).
Table 1 Sociodemographic data of the studied group $(n=450)$

\begin{tabular}{|c|c|c|}
\hline Character & Mean \pm SD & Range \\
\hline Age of the patient & $31.68 \pm 9.26$ & $18-66$ \\
\hline Age at marriage (years) & $19.43 \pm 3.69$ & $12-40$ \\
\hline Age of the husband (years) & $38.33 \pm 10.85$ & $22-75$ \\
\hline \multirow[t]{2}{*}{ Sex frequency (per week) } & $2.44 \pm 0.85$ & $1-7$ \\
\hline & No. & $\%$ \\
\hline \multicolumn{3}{|l|}{ Educational level } \\
\hline Illiterate & 106 & 23.6 \\
\hline Basic & 87 & 19.3 \\
\hline Secondary & 170 & 37.8 \\
\hline High & 87 & 19.3 \\
\hline \multicolumn{3}{|l|}{ Occupation } \\
\hline Working & 101 & 22.4 \\
\hline Not working & 349 & 77.6 \\
\hline \multicolumn{3}{|l|}{ Comorbidities } \\
\hline Present & 72 & 16.0 \\
\hline Absent & 378 & 84.0 \\
\hline \multicolumn{3}{|l|}{ Contraception } \\
\hline Yes & 293 & 65.1 \\
\hline No & 157 & 34.9 \\
\hline \multicolumn{3}{|l|}{ Menstrual cycle } \\
\hline Regular & 273 & 60.7 \\
\hline Irregular & 177 & 39.3 \\
\hline \multicolumn{3}{|l|}{ Gynecological disorders } \\
\hline Absent & 347 & 77.1 \\
\hline Fungal infection & 95 & 21.1 \\
\hline Uterine contractions & 1 & 0.2 \\
\hline Uterine prolapse & 3 & 0.7 \\
\hline Genital wart & 1 & 0.2 \\
\hline Genital ulcer & 2 & 0.4 \\
\hline Uterine adhesions & 1 & 0.2 \\
\hline
\end{tabular}

Pain score had significant negative correlation with each of the depression score $(r-0.524, p<0.001)$ and the anxiety score $(r-0.305, p<0.001)$ (Fig. 2).

There was no significant relation between the pain severity and different grades of the educational level, working status, comorbidities, menstrual cycle rhythm, contraception, or circumcision. Fungal infection, severe depression, and severe anxiety were significantly associated with marked severe pain. Patients with fungal infection had significantly marked severe pain than patients without any physical causes $(<0.001)$. Patients with severe depression had significantly marked severe pain than patients with minimal depression $(p<0.001$ respectively). Patients with severe anxiety had significantly lower pain score than patients without $(p<0.001)$ (Tables 3 and 4$)$. 
Table 2 Psychiatric diagnosis among the studied females

\begin{tabular}{ll}
\hline Diagnosis & No. (\%) \\
\hline Depression & $375(83.3)$ \\
Absent & $75(16.7)$ \\
Present & \\
Depression severity & $375(83.3)$ \\
Minimal & $1(0.2)$ \\
Mild & $11(2.4)$ \\
Moderate & $63(14.0)$ \\
Severe & \\
Anxiety & $410(91.1)$ \\
Absent & $40(8.9)$ \\
Present & \\
Anxiety severity & $410(91.1)$ \\
Minimal & $2(0.4)$ \\
Moderate & $38(8.4)$ \\
Severe &
\end{tabular}

Univariate and multivariate linear regression revealed that depression, anxiety, and the presence of gynecological causes were significantly independent risk factors for more sexual pain (Table 5).

\section{Discussion}

Female sexual dysfunction is an irritating issue that is hard to be assessed in the Middle East countries due to its sensitive nature and the conservative traits of the population [19].

The prevalence of marked severe sexual pain in the study group was $31.6 \%$ of the studied group and the prevalence of trivial pain was $68.4 \%$ of the studied group. This was consistent with the global prevalence of the
World Health Organization in 2006 that reported global prevalence of female sexual pain ranging between 8 and $21.1 \%$ [20] and also, consistent with systematic review in Brazil in 2016 that reported the prevalence of female sexual pain ranged from 1.2 to $56.1 \%$ [21].

In the present study, patients with gynecological causes especially fungal infection had significantly severe marked pain than patients without any other physical causes $(<0.001)$. This was consistent with Oshinowo et al. [22] whom showed that female sexual pain is believed to be a specific sexual pain disorder that can be accompanying vulvovaginitis.

In the present study, the most common cause of gynecological causes of female sexual pain was fungal infections 95 (21.1\%) females. This was consistent with Nyirjesy [23] who stated that the most common etiology of chronic vaginal pain is recurrent vaginal fungal infection.

About $75 \%$ of women develop a fungal infection during their lifetime. Further studies indicate that five percent of women with vaginal fungal infections may develop recurrent vulvovaginal candidiasis [24].

The common symptoms of vulvovaginal fungal infection include pain during sexual intercourse [24, 25].

In the present study, there was no statistically significant relation between severity of pain and wives' health problems, menstrual cycle, contraception and circumcision, education level of wives, and wives' work. This was consistent with Selahittin et al. [26] who stated that there were no significant differences detected in marriage age, previous pelvic surgery, and contraception methods used between the women with and without sexual dysfunction including pain; however, they showed significantly higher prevalence of sexual dysfunction in the presence of older age, lower educational level, and unemployment, also, disagreed with Laumann et al. [27] who stated that low educated, unemployed, with chronic

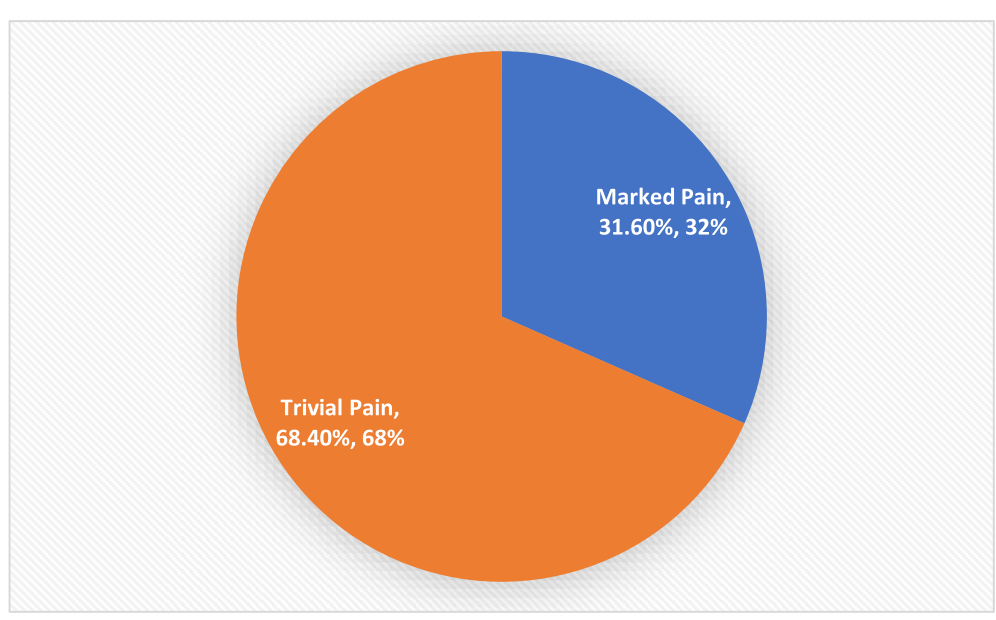

Fig. 1 Prevalence of female sexual pain 


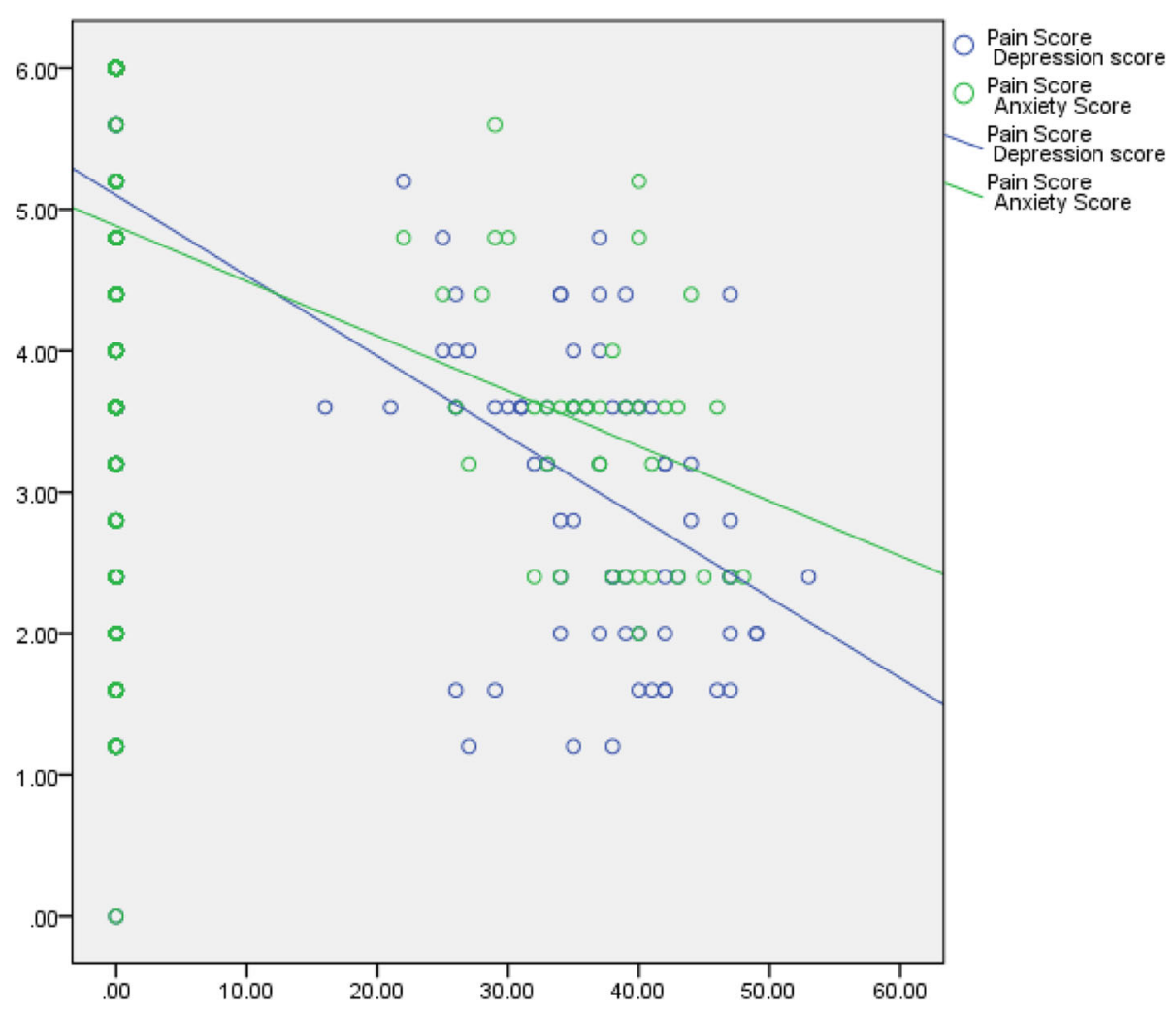

Fig. 2 Overlay scatter plot for pain score with depression score and anxiety score

disease, multi-parried, and menopaused females had high risk of complaining of sexual problems.

In this study, patients with severe depression had significantly marked severe pain than patients with minimal depression $(p<0.001$ respectively), which means that females suffered higher levels of depression and had higher marked pain and higher feeling of sexual pain more than others.

This was consistent with Atlantis and Sullivan [28] and Evan and Thomas [29] who stated that the chance of having sexual dysfunction including pain (which is the aim of this study) as well as desire, arousal, satisfaction, and orgasm is increased by depression. Also, it was consistent with Frohlich and Meston [30] who reported that depressive women felt higher sexual pain, along with low sexual arousal than controls without depression.

In this study, patients with severe anxiety had significantly lower pain score than patients without $(p<0.001)$, which means that females who suffered from higher levels of anxiety had higher marked pain and a higher feeling of sexual pain more than others. That confirms the positive correlation between sexual pain and anxiety. And this was consistent with Kimberley et al. [31] who stated that hyper vigilance to pain stimuli in women suffering anxiety may result in both a heightened awareness of pain and a distraction away from sexual stimuli resulting in impaired sexual arousal, which itself may potentially exacerbate the pain experience. Also, this agreed with Payne et al. [31] who stated that women with anxiety who usually have high threshold to pain stimuli would over expect the feeling of pain and subsequently would distract away from sexual stimuli that eventually would lead to impaired sexual function. That itself may potentially augment the pain experience.

In the present study, pain score (low pain scores means high degree and high frequency of pain) had significant negative correlation with each of the depression score $(r-0.524, p<0.001)$ and the anxiety score $(r-0.305, p<0.001)$. This agreed with Rossi et al. [5] and Burri et al. [32] who found that female sexual pain had significant anxiety $(p$ value $<0.01)$ and depression $(p$ value $<0.01)$.

In the present study, univariate and multivariate linear regression revealed that depression anxiety and the presence of gynecological causes especially fungal infections were significantly independent risk factors for more sexual pain. Similarly, Khandker et al. [33] found that anxiety and depression were an independent risk factor for female sexual pain that increases the risk of such disorders, highlighting the bidirectional temporal relationship between sexual pain and such psychiatric symptoms. Although the relationship between painful sexual intercourse 
Table 3 Association of the pain score with different risk factors

\begin{tabular}{|c|c|c|}
\hline Risks factors & Pain score mean \pm SD & $P$ value \\
\hline \multicolumn{3}{|l|}{ Educational level } \\
\hline Illiterate & $4.89 \pm 1.45$ & \multirow[t]{4}{*}{0.634} \\
\hline Basic & $4.81 \pm 1.52$ & \\
\hline Secondary/intermediate & $4.66 \pm 1.55$ & \\
\hline High & $4.70 \pm 1.45$ & \\
\hline \multicolumn{3}{|l|}{ Occupation status } \\
\hline Working & $4.81 \pm 1.52$ & \multirow[t]{2}{*}{0.675} \\
\hline Not working & $4.74 \pm 1.50$ & \\
\hline \multicolumn{3}{|l|}{ Comorbidities } \\
\hline Present & $4.81 \pm 1.42$ & \multirow[t]{2}{*}{0.719} \\
\hline Absent & $4.74 \pm 1.52$ & \\
\hline \multicolumn{3}{|l|}{ Menstrual cycle rhythm } \\
\hline Regular & $4.76 \pm 1.49$ & \multirow[t]{2}{*}{0.843} \\
\hline Irregular & $4.73 \pm 1.52$ & \\
\hline \multicolumn{3}{|l|}{ Contraception } \\
\hline Yes & $4.71 \pm 1.55$ & \multirow[t]{2}{*}{0.492} \\
\hline No & $4.82 \pm 1.41$ & \\
\hline \multicolumn{3}{|l|}{ Circumcision } \\
\hline Yes & $4.75 \pm 1.51$ & \multirow[t]{2}{*}{0.866} \\
\hline No & $4.79 \pm 1.42$ & \\
\hline \multicolumn{3}{|l|}{ Gynecological causes } \\
\hline Absent & $5.08 \pm 1.44$ & \multirow[t]{7}{*}{$<0.001$} \\
\hline Fungal infection & $3.76 \pm 1.09^{\mathrm{a}}$ & \\
\hline Uterine contractions & 3.60 & \\
\hline Uterine prolapse & $2.80 \pm 1.38$ & \\
\hline Genital wart & 2.40 & \\
\hline Genital ulcer & $1.80 \pm 0.28$ & \\
\hline Uterine adhesions & 1.20 & \\
\hline \multicolumn{3}{|l|}{ Presence of depression } \\
\hline Absent & $5.10 \pm 1.34$ & \multirow[t]{2}{*}{$<0.001$} \\
\hline Present & $3.02 \pm 0.99$ & \\
\hline \multicolumn{3}{|l|}{ Depression severity } \\
\hline Minimal & $5.10 \pm 1.34$ & \multirow[t]{4}{*}{$<0.001$} \\
\hline Mild & 3.60 & \\
\hline Moderate & $3.63 \pm 1.21^{\mathrm{b}}$ & \\
\hline Severe & $2.91 \pm 0.92^{b}$ & \\
\hline \multicolumn{3}{|l|}{ Presence of anxiety } \\
\hline Absent & $4.88 \pm 1.49$ & \multirow[t]{2}{*}{$<0.001$} \\
\hline Present & $3.49 \pm 0.90$ & \\
\hline \multicolumn{3}{|l|}{ Anxiety severity } \\
\hline Minimal & $4.88 \pm 1.49$ & \multirow[t]{3}{*}{$<0.001$} \\
\hline Moderate & $4.60 \pm 0.28$ & \\
\hline Severe & $3.43 \pm 0.88^{c}$ & \\
\hline
\end{tabular}

${ }^{a}$ Patients with fungal infection had significantly lower pain score than patients without any physical causes $(<0.001)$

${ }^{b}$ Patients with moderate and severe depression had significantly lower pain score than patients with minimal depression $(p 0.008$ and $<$ 0.001 respectively)

'Patients with severe anxiety had significantly lower pain score than patients without $(p<0.001)$ 
Table 4 Relation between pain severity and different risk factors

\begin{tabular}{|c|c|c|c|c|}
\hline \multirow[t]{2}{*}{ Risks factors } & \multicolumn{2}{|l|}{ Pain severity } & \multirow[t]{2}{*}{ Total } & \multirow[t]{2}{*}{$P$ value } \\
\hline & Marked pain $(n=142)$ & Trivial pain $(n=308)$ & & \\
\hline \multicolumn{5}{|l|}{ Educational level } \\
\hline Illiterate & $31(21.8)$ & $75(24.4)$ & $106(23.6)$ & \multirow[t]{4}{*}{0.874} \\
\hline Basic & $26(18.3)$ & $61(19.8)$ & $87(19.3)$ & \\
\hline Secondary/intermediate & $57(40.1)$ & $113(36.7)$ & 170 (37.8) & \\
\hline High & $28(19.7)$ & $59(19.2)$ & $87(19.3)$ & \\
\hline \multicolumn{5}{|l|}{ Working status } \\
\hline Working & $26(18.3)$ & $75(24.4)$ & $101(22.4)$ & \multirow[t]{2}{*}{0.153} \\
\hline Not working & $116(81.7)$ & 233 (75.6) & 349 (77.6) & \\
\hline \multicolumn{5}{|l|}{ Comorbidities } \\
\hline Present & $23(16.2)$ & $49(15.9)$ & $72(16.0)$ & \multirow[t]{2}{*}{0.938} \\
\hline Absent & $119(83.8)$ & $259(84.1)$ & $378(84.0)$ & \\
\hline \multicolumn{5}{|l|}{ Menstrual cycle } \\
\hline Regular & $84(59.2)$ & $189(61.4)$ & $273(60.7)$ & \multirow[t]{2}{*}{0.656} \\
\hline Irregular & $58(40.8)$ & $119(38.6)$ & $177(39.3)$ & \\
\hline \multicolumn{5}{|l|}{ Contraception } \\
\hline Yes & $96(67.6)$ & $197(64.0)$ & $293(65.1)$ & \multirow[t]{2}{*}{0.451} \\
\hline No & $36(32.4)$ & $111(36.0)$ & $157(34.9)$ & \\
\hline \multicolumn{5}{|l|}{ Circumcision } \\
\hline Yes & $127(89.4)$ & 276 (89.6) & 403 (89.6) & \multirow[t]{2}{*}{0.955} \\
\hline No & 15 (10.6) & $32(10.4)$ & $47(10.4)$ & \\
\hline \multicolumn{5}{|l|}{ Gynecological disorders } \\
\hline Absent & $89(62.7)$ & $258(83.8)$ & $347(77.1)$ & \multirow[t]{7}{*}{$<0.001$} \\
\hline Fungal infection & $45(31.7)^{\mathrm{a}}$ & $50(16.2)$ & $95(21.1)$ & \\
\hline Uterine contractions & $1(0.7)$ & $0(0.0)$ & $1(0.2)$ & \\
\hline Uterine prolapse & $3(2.1)$ & $0(0.0)$ & $3(0.7)$ & \\
\hline Genital wart & $1(0.7)$ & $0(0.0)$ & $1(0.2)$ & \\
\hline Genital ulcer & $2(1.4)$ & $0(0.0)$ & $2(0.4)$ & \\
\hline Uterine adhesions & $1(0.7)$ & $0(0.0)$ & $1(0.2)$ & \\
\hline \multicolumn{5}{|l|}{ Presence of depression } \\
\hline Absent & $81(57.0)$ & $294(95.5)$ & $375(83.3)$ & \multirow[t]{2}{*}{$<0.001$} \\
\hline Present & $61(43.0)$ & $14(4.5)$ & $75(16.7)$ & \\
\hline \multicolumn{5}{|l|}{ Depression severity } \\
\hline Minimal & $81(57.4)$ & $294(95.5)^{b}$ & $375(83.5)$ & \multirow[t]{3}{*}{$<0.001$} \\
\hline Moderate & $5(3.5)$ & $6(1.9)$ & $11(2.4)$ & \\
\hline Severe & $55(39.0)^{b}$ & $8(2.6)$ & $63(14.0)$ & \\
\hline \multicolumn{5}{|l|}{ Presence of anxiety } \\
\hline Absent & $112(78.9)$ & $298(96.8)$ & $410(91.1)$ & \multirow[t]{2}{*}{$<0.001$} \\
\hline Present & $30(21.1)$ & $10(3.2)$ & $40(8.9)$ & \\
\hline \multicolumn{5}{|l|}{ Anxiety severity } \\
\hline Minimal & $112(78.9)$ & $298(96.8)^{c}$ & $410(91.1)$ & $<0.001$ \\
\hline Moderate & $0(0.00$ & $2(0.6)$ & $2(0.4)$ & \\
\hline Severe & $30(21.1)^{c}$ & $8(2.6)$ & $38(8.4)$ & \\
\hline
\end{tabular}

Patients with fungal infection had significantly severe marked pain than patients without any physical causes $(<0.001)$

${ }^{\mathrm{b}}$ Patients with severe depression had significantly severe marked pain than patients without depression $(p<0.001)$

'Patients with severe anxiety had significantly severe marked pain than patients without anxiety $(p<0.001)$ 
Table 5 Univariate linear regression of pain score with different risk factors

\begin{tabular}{|c|c|c|c|c|}
\hline \multirow[t]{2}{*}{ Risk factors } & \multicolumn{2}{|c|}{ Univariate } & \multicolumn{2}{|c|}{ Multi variate } \\
\hline & $B$ & $\overline{P \text { value }}$ & $B$ & $P$ value \\
\hline Age of the patient & 0.008 & 0.271 & $\begin{array}{c}--- \\
--1\end{array}$ & $\begin{array}{ll}--- \\
-\end{array}$ \\
\hline Contraception & 0.130 & 0.354 & - & - \\
\hline Work status & -0.071 & 0.675 & - & --- \\
\hline Menstrual cycle & -0.029 & 0.843 & ---- & - \\
\hline Circumcision & 0.039 & 0.866 & ---- & ---- \\
\hline Comorbidity & -0.082 & 0.668 & ---- & ---- \\
\hline Gynecological causes & -0.903 & $<0.001$ & -1.302 & $<0.001$ \\
\hline Depression & -2.073 & $<0.001$ & -2.648 & $<0.001$ \\
\hline Anxiety & -0.695 & $<0.001$ & -1.065 & $<0.001$ \\
\hline
\end{tabular}

and depressive and anxiety symptoms is well-documented, the factors that are driving this relationship and the temporal associations among these factors have yet to be elucidated.

Also, females who feel sexual pain are likely to complain from psychiatric symptoms, in particular increased depressive symptoms [33-36].

Several study limitations should be taken in consideration. First, the cross-sectional nature of this study could not confirm the temporal relationships between sexual pain and psychiatric symptoms. Further longitudinal or experimental designs would further elucidate the directionality of these relationships. Second, other studies are needed to know how other comorbid pain factors are correlated with sexual functioning and psychiatric symptoms. Third, future studies should examine these relationships in women who are not currently sexually active, as pain during intercourse might prevent women from engaging in sexual intercourse.

\section{Conclusion}

Depression anxiety and gynecological causes especially fungal infections were independent risk factors for female sexual pain. We strongly recommended putting into consideration the importance of searching for psychiatric disorders during assessment and treatment of females suffering from sexual pain. And the urgent need for an integrated approach with co-operation between sexologists and psychiatrists in this conflict.

\section{Abbreviations}

FSFI: Female sexual function index

\section{Acknowledgements}

The authors thank subjects for their participation and cooperation.

\section{Authors' contributions}

$\mathrm{TA}, \mathrm{MR}, \mathrm{NM}, \mathrm{SS}$, and $\mathrm{BH}$ analyzed and interpreted the patient data regarding the clinical data and psychometric tools, and all authors were contributors in writing the manuscript. All authors have read and approved the final manuscript.

\section{Funding}

This study did not receive any fund.

Availability of data and materials

Not applicable.

Ethics approval and consent to participate

This study was approved by the Ethics Committee of Faculty of Medicine, Menoufia University. Written informed consents were obtained from subjects of the study. The number of approvals is not applicable.

Consent for publication

Not applicable.

\section{Competing interests}

"The authors declare that they have no competing interests" in this section.

\section{Author details}

${ }^{1}$ Department of Psychiatry, Faculty of Medicine, Fayoum University, P.O. Box 63514, Fayoum, Egypt. ²Department of Dermatology, Faculty of Medicine, Fayoum University, Fayoum, Egypt. ${ }^{3}$ Department of Public Health and Community Medicine, Faculty of Medicine, Menoufia University, Shibin El Kom, Egypt.

Received: 29 July 2020 Accepted: 23 September 2020

Published online: 08 December 2020

\section{References}

1. Danielsson I, Sjöberg I, Stenlund H, Wikman M (2003) Prevalence and incidence of prolonged and severe dyspareunia in women: results from a population study. Scand J Publ Health 31(2):113-118 [PubMed] [Google Scholar]

2. Jamieson DJ, Steege JF(1996).The prevalence of dysmenorrhea, dyspareunia, pelvic pain, and irritable bowel syndrome in primary care practicesObstet Gynecol 87(1):55-58 [PubMed] [Google Scholar]

3. Landry T, Bergeron S. (2009).How young does vulvo-vaginal pain begin? Prevalence and characteristics of dyspareunia in adolescentsJ Sex Med.6(4): 927-935. [PubMed] [Google Scholar]

4. American Psychiatric Association (2013) Diagnostic and statistical manual of mental disorders, vol 5. American Psychiatric Publishing, Arlington, VA [Google Scholar]

5. Rossi V, Viozzi E, Tripodi F, Nimbi FM, Fabrizi A, Simonelli C (2017) Female sexual pain and psycho-relational correlates: preliminary results of the Italian survey "sexuality and well-being.". J Sex Med 14:112. https://doi.org/10.1016/ j.jsxm.2017.03.088

6. Annamaria G, Alessandra $H$, James $P$, Ellen L (2013) Female sexual arousal disorders. J Sex Med 10(1):58-73

7. Alessandra G, Dania G (2017) Evaluation of genito-pelvic pain penetration disorder. In: The text book of clinical sexual medicine, springer international publishing, pp 289-304

8. Rosen R, Brown C, Heiman J, Leiblum S, Meston C, Shabsigh R, Ferguson D, D'Agostino R Jr (2000) The female sexual function index (FSFI): a multidimensional self-report instrument for the assessment of female sexual function. J Sex Marital Ther 26(2):191-208. https://doi.org/10.1080/ 009262300278597

9. Anis TH, Gheit SA, Saied HS, Al Kherbash SA (2011) Arabic translation of female sexual function index and validation in an Egyptian population. $J$ Sex Med 8:3370-3378

10. First MB, Gibbon M, Spitzer RL, Williams JBW (2002) Structured clinical interview for DSM-IV-TR axis I disorders. Biometrics Research Department, New York

11. Hatata, Abou zeid, Khalil, et al. (2004). Dual diagnosis in substance abuse, a study in an Egyptian sample. MD thesis, Ain Shams University.

12. Beck AT, Ward CH, Mendelson M, Mock J, Erbaugh J (1961) An inventory for measuring depression. Arch Gen Psychiatry 4:561-571

13. Abdel-Khalek AM (1998) Internal consistency of an Arabic adaptation of the Beck Depression Inventory in four Arabic countries. Psychol Rep 82:264-266

14. Beck AT, Steer RA, Ball R et al (1996) Comparison of Beck Depression Inventories-IA and -II in psychiatric outpatients. J Person Assess 67:588-597 
15. Beck AT, Steer RA, Garbin MG (1988) Psychometric properties of the Beck Depression Inventory: twenty-five years of evaluation. Clin Psychol Rev 8:77-100

16. Al-Issa I, Al Zubaidi A, Bakal D (2000) Beck Anxiety Inventory symptoms in Arabic college students. Arabic J Psychiatry 11:41-47

17. Snedecor GW, Cochran WG (1980) Statistical methods, 7th edn. lowa State University Press, Ames, lowa

18. Hr̃dle W, Simar L (2007) Applied multivariate statistical analysis. SpringerVerlag Berlin Heidelberg, New York

19. Shaeer F, Sultan A, Dar S (2012) Depression and prevalence of sexual dysfunction. Pakistan J Med Res 43(3):104-107

20. Sorensen J, Bautista KE, Lamvu G, Feranec J (2018) Evaluation and treatment of female sexual pain: a clinical review. Cureus 10(3)

21. Wolpe RE, Zomkowski K, Silva FP, Queiroz APA, Sperandio FF (2017) Prevalence of female sexual dysfunction in Brazil: a systematic review. European J Obstet Gynecol Reprod Biol 211:26-32

22. Oshinowo A, Ionescu A, Anim TE, Lamvu G $(2016,2016)$ Pelvic pain management. Oxford University Press Dyspareunia and vulvodynia. [Google Scholar]

23. Nyirjesy, P., (2001). Chronic vulvovaginal candidiasis. American family physician, 63(4), p.697.

24. Sobel JD, Faro S, Force RW, Foxman B, Ledger WJ, Nyirjesy PR (1998) Vulvovaginal candidiasis: epidemiologic, diagnostic, and therapeutic considerations. Am J Obstet Gynecol. 178:203-211

25. Gonçalves B, Ferreira C, Alves CT, Henriques M, Azeredo J, Silva S (2016) Vulvovaginal candidiasis: epidemiology, microbiology and risk factors external icon. Criti Rev Microbiol 42:905-927

26. Selahittin C, Erdem A, Murat B, Bülent C, Deniz A, Ercüment U (2004) The prevalence of female sexual dysfunction and potential risk factors that may impair sexual function in Turkish women. Department of Urology, University of Mersin School of Medicine, Mersin, Turkey: urologia internationalis 72:52-57

27. Laumann EO, Paik A, Rosen RC (1999) Sexual dysfunction in the United States: prevalence and predictors. J Am Med Assoc 281(6):537-544. https:// doi.org/10.1001/jama.281.6.537

28. Atlantis E, Sullivan T (2012) Bidirectional association between depression and sexual dysfunction: a systematic review and meta-analysis. J Sex Med 9(6):1497-1507. https://doi.org/10.1111/j.1743-6109.2012.02709.x

29. Evan A, Thomas S (2012) Biderectional association between depression and sexual dysfunction: a systemic review and meta- analysis. J Sex Med 9(6): 1497-1507

30. Frohlich P, Meston C (2002) Sexual functioning and self-reported depressive symptoms among college women. J Sex Res 39(4):321-325. https://doi.org/ 10.1080/00224490209552156

31. Kimberley A, Yitzchak M, Ronda A, Samir K (2005) When sex hurts anxiety and fear orient attention towards pain. Eur J Pain 9(4):427

32. Burri A, Ogata S, Williams F (2017) Female sexual pain: epidemiology and genetic overlap with chronic widespread pain. Eur J Pain 21(8):1408-1416. https://doi.org/10.1002/ejp.1042

33. Khandker M, Brady SS, Vitonis AF, MacLehose RF, Stewart EG, Harlow BL (2011) The influence of depression and anxiety on risk of adult onset vulvodynia. J Women's Health 20(10):1445-1451 [PMC free article] [PubMed] [Google Scholar]

34. Boerner KE, Rosen NO (2015) Acceptance of vulvovaginal pain in women with provoked vestibulodynia and their partners: associations with pain, psychological, and sexual adjustment. J Sexual Med 12(6):1450-1462 [PubMed] [Google Scholar]

35. Santos PR, Capote JRFG Jr, Cavalcanti JU, Vieira CB, Rocha ARM, Apolônio NAM et al (2013) Sexual dysfunction predicts depression among women on hemodialysis. Int Urology Nephrology 45(6):1741-1746 [PubMed] [Google Scholar]

36. Schnatz PF, Whitehurst SK, O'Sullivan DM (2010) Sexual dysfunction, depression, and anxiety among patients of an inner-city menopause clinic. J Women's Health 19(10):1843-1849 [PubMed] [Google Scholar]

\section{Publisher's Note}

Springer Nature remains neutral with regard to jurisdictional claims in published maps and institutional affiliations.

\section{Submit your manuscript to a SpringerOpen ${ }^{\circ}$ journal and benefit from:}

- Convenient online submission

- Rigorous peer review

- Open access: articles freely available online

- High visibility within the field

- Retaining the copyright to your article

Submit your next manuscript at $\boldsymbol{\nabla}$ springeropen.com 